\title{
Semiconductors
}

Amorphous and Liquid Semiconductors. Edited by J. Tauc. Pp. ix +441 . (Plenum: London and New York, 1974.) $\$ 33.60$.

INTEREST in the field of amorphous semiconductors has increased rapidly during the last 10 ycars because of the obvious commercial success of the Xerox process and the possible commercial success of the amorphous switching device. Before that, technical interest in the amorphous state was sustained by those interested in photoconductors as potential light sensors and in glass technology; and fundamental studics derived largely from intcrest in the liquid state and in the development of general methods for defining order and disorder in solids.

The graph of interest against time has probably now flattened off and major discoveries are appearing more slowly; meanwhile, several reviews of the field have appcarcd in book form. It is a good time to ask if these books tell us whether we have got anywhere in understanding amorphous semiconductors, and whether it is worth sustaining any interest. The questions come to mind because the first clear message from all of the works is that the fundamental problems of under-

\section{New from IRL}

\section{Obesity}

A Bibliography 1964-1973

263 pages $£ 10.00 /$ US $\$ 25.00$

ISBN 0904147010

Contains over 2,000 references to publications dealing with all aspects of obesity and related topics which have appeared during the last 10 years in major journals from a wide range of disciplines.

\section{Transduction \\ Mechanisms in Chemoreception}

Proceedings of a Symposium organized in September 1973 by the

European Chemoreception Research Organization.

408 pages $66.00 /$ US $\$ 15.00$ ISBN 0904147002

Contains 21 papers and the ensuing discussions at this important meet. ing of biologists of many disciplines discussing the mechanisms by which taste and smell receptors respond to specific molecules

\section{Information Retrieval Ltd.}

standing amorphous solids are very difficult, and the experimental problems, such as control in preparation and the significance of measurements, are considcrable. Will the strenuous efforts which are still required to solve the problems repay us to a similar extent as, say, an equal amount of work on new crystalline semiconductors?

The collection of chapters edited by Dr Tauc certainly has the depth to give the reader a chance to address the question: the extensive and thoughtful reviews are presented by some of the most respected workers in the field. To this depth the editor has added a suitable breadth by selecting authors who have a suitable diversity of viewpoint. Some freshness is added by the inclusion of authors who have not yet received very wide exposure.

Bagley, a less well known author, draws a distinction between glasses and other amorphous materials, emphasising that the structure obtained from the cooling of a liquid will be "structurally and thermodynamically related to that liquid" but that similarities between those glasses and "other amorphous solids" may be tenuous. Such a caveat is a useful corrective to carry into the other chapters, which seck mainly to cxplain the electrical and optical properties of that class of 'other amorphous solids'.

Of the chapters which review large volumes of data, Tauc's and Fritzsche's are excellently condensed, although Tauc sometimes relapses into singlesentence listing without further observation and, in the end, shirks a conclusion. Fritzsche, by contrast, ends his chapter on electronic properties with a precise and frank summary of the gulf which still exists between experiment and theory in the field of electrical transport. He stresses that many amorphous semiconductor films contain heterogeneous voids and that this may invalidate many of the theories based on measurements of conductivity, elastoresistance and thermopower.

In his second chapter, Fritzsche gives a summary of the chemical requirements for the components of a switching or memory alloy. In such paragraphs, one feels that one is getting the distillation of a huge amount of research in a few sentences and that the book is thereby achieving its intention-that of a mature review.

Girgorivici has managed similarly to condense knowledge in a lively review of the mode in which atoms pack and bond in known amorphous materials. Econonomou, Cohen and others give a highly condensed summary of the necessary band and percolation theory.

The book represents a useful reference volume and is a very good starting point for those who wish to understand the field.

A. G. Holmes-Siedle

\section{Affinity chromatography}

Affinity Chromatography. By C. R. Lowe and P. D. G. Dcan. Pp.xi+272. (Wiley-Interscience: London and New York, September 1974.) $£ 6.25$

THIS book would be a valuable asset to any research group working in fields such as enzymology and protein chemistry in which an awareness of the principles and potentialities of affinity chromatography must now be considered obligatory. The original literature on affinity chromatography is now considerable and an introductory text was badly needed. Both the length and the price of this book have been well judged.

The reader should not he put off by the first part of the introduction in Chapter I as I almost was. It consists of three pages on protein structure, which are entircly superfluous for anyone who is at all familiar with proteins, and which certainly would not help anyone who was not. The flatvour of those three pages is unfortunate: for example, the common acidic and basic groups of amino acids are wrongly assigned as in the worst undergraduate texts, peptide bond formation is stated to "occur" by elimination of a water molecule, of all things, and that is illustrated by a "lasso" in Iiig. I.1. The structurc of the indole ring of tryptophan (Table I.1) is wrong and the hydrogen atom of the imidazole $\mathrm{N}-\mathrm{H}$ bond is missing, as indeed it is throughout the book.

Happily, after that the presentation improves dramatically. Most sections provide a short but helpful discussion of theoretical aspects followed by interesting examples well illustrated by elution diagrams and by structural formulae where appropriate. This is particularly helpful in a book that deals with many different types of molecules and which is aimed at a wide readership that must include people not normally used to thinking in molecular terms. Although many of the theoretical sections are, of necessity, brief they do provide very useful starting points for further rcading. All sections of the book are well supported by literature references up to mid 1973. Following an introductory chapter, there are four main chapters. These deal with the principles of affinity chromatography: group specific absorbents: various applications of affinity chromatography, including hydrophobic chromatography; and the organic chemistry of materials used in affinity chromatography, particularly the reactions involved in the preparation of various affinity adsorbents. K. Brocklehurst 